\title{
1 Grapevine rootstocks affect growth-related scion phenotypes
}

2 Running title: Grapevine rootstocks affect scion growth

3 Zoë Migicovsky ${ }^{1 *}$, Peter Cousins ${ }^{2}$, Lindsay M. Jordan ${ }^{3}$, Sean Myles ${ }^{1}$, Richard Keith Striegler ${ }^{3}$,

$4 \quad$ Paul Verdegaal ${ }^{4}$, Daniel H. Chitwood ${ }^{5,6^{*}}$

$6 \quad{ }^{1}$ Department of Plant, Food and Environmental Sciences, Faculty of Agriculture, Dalhousie

7 University, Truro, NS B2N 5E3, Canada

$8 \quad{ }^{2}$ E. \& J. Gallo Winery, Modesto, CA, 95354, USA

$9 \quad{ }^{3}$ E. \& J. Gallo Winery, Acampo, CA 95220, USA

$10{ }^{4}$ University of California Cooperative Extension, San Joaquin Valley, Stockton, CA, 95206,

11 USA

12 5epartment of Horticulture, Michigan State University, East Lansing, Michigan, 48824, USA

$13{ }^{6}$ Department of Computational Mathematics, Science and Engineering, Michigan State

14 University, East Lansing, Michigan, 48824, USA

15

$16 *$ Corresponding authors

17 Zoë Migicovsky: zoe.migicovsky@dal.ca

18 Daniel H. Chitwood: dhchitwood@gmail.com

19

20 Keywords: rootstocks, grafting, grapevines, root-shoot interactions

21 


\section{Abstract}

26 Grape growers use rootstocks to provide protection against pests and pathogens and to modulate

27 viticulture performance such as shoot growth. Our study examined two grapevine scion varieties

28 ('Chardonnay' and 'Cabernet Sauvignon') grafted to 15 different rootstocks and determined the

29 effect of rootstocks on eight traits important to viticulture. We assessed the vines across five

30 years and identified both year and variety as contributing strongly to trait variation. The effect of

31 rootstock was relatively consistent across years and varieties, explaining between $8.99 \%$ and

$329.78 \%$ of the variation in growth-related traits including yield, pruning weight, berry weight, and

33 Ravaz index (yield to pruning weight ratio). Increases in yield due to rootstock were generally

34 the result of increases in berry weight, likely due to increased water uptake by vines grafted to a

35 particular rootstock. We demonstrated a greater than $50 \%$ increase in yield, pruning weight, or

36 Ravaz index by choosing the optimal rootstock, indicating that rootstock choice is crucial for

37 grape growers looking to improve vine performance.

\section{Introduction}

41 Grafting joins two distinct plant parts: a scion (shoot system) from a donor plant and a rootstock

42 (root system) from a second plant to which the scion is attached. The practice of grafting chiefly

43 enables clonal propagation but can also have many other benefits, such as reducing the juvenility

44 period (increasing precocity) or size (dwarfing) in fruit trees ${ }^{1-3}$. 
In grapevines (Vitis vinifera L.), widespread use of grafting began in the late 1800s, following the introduction of phylloxera (Daktulosphaira vitifoliae Fitch) to Europe from North America. While $V$. vinifera is highly susceptible to phylloxera, which feeds on the roots of grapevines, eastern North American Vitis species evolved in the presence of phylloxera and are tolerant and/or resistant to it. By grafting $V$. vinifera scions to rootstocks of other Vitis species, $V$. vinifera could be grown in European soils containing phylloxera, rescuing the wine industry ${ }^{4}$.

Ten years after its detection in Europe, own-rooted (ungrafted) grapevines with phylloxera were

first identified in California. The inter-continental spread of the pest was likely due to the importation of vines from European nurseries or from eastern North America ${ }^{5}$. However, due to the sandy soils of California's Central Valley (or San Joaquin Valley, specifically), phylloxera infections were not as severe and did not require the immediate use of rootstocks ${ }^{6}$. By the 1950 s, less than $30 \%$ of California grapevines were grafted onto phylloxera-resistant rootstocks ${ }^{7}$. Still, over time, the California grapevine industry transitioned primarily to grafted vines. Currently, more than $80 \%$ of vineyards worldwide grow grafted vines ${ }^{4}$.

In addition to allowing $V$. vinifera vines to grow in phylloxera-infested soils, grapevine

63 rootstocks can provide tolerance to several other damaging pests and diseases including root-

64 knot and dagger nematodes ${ }^{8-10}$. Rootstocks may also be used to improve resilience to abiotic

65 stresses such as salinity ${ }^{11}$ and drought ${ }^{12}$. Grafting grapevines to a particular rootstock can

66 influence a wide range of traits in the scion including mineral composition ${ }^{13-15}$, berry

67 chemistry $^{16}$, and berry maturation ${ }^{17}$. 
Of particular interest to grape growers is the observation that rootstock choice can affect vine size and yield ${ }^{18}$. While other factors such as climate and location exceed the influence of rootstock on grapevine growth ${ }^{19,20}$, numerous studies have provided evidence of the impact

72 rootstock can have on yield ${ }^{18,21,22}$. For a grape grower, an increase in yield is desirable, but

73 increasing vine size or vegetative growth also increases the cost of managing the vine, due to

74 additional labour for vine training, pruning, and fruit thinning. An ideal rootstock will increase

75 reproductive growth, or yield, without an accompanying increase in vegetative growth, which is

76

77 variation. assessed by measuring pruning weight or the amount of one-year-old dormant cuttings removed during the winter. The Ravaz index, or yield divided by pruning weight from the following dormant season, can be calculated to determine the relative ratio of reproductive to vegetative growth. The impact that rootstocks can have on berry composition is generally thought to be an indirect effect as a result of their impact on vegetative and reproductive growth, for example by altering water or nutrient uptake ${ }^{19,23}$.

With all the potential benefits offered by a rootstock, deciding which one to use is an important choice. While other changes to vineyard management can be made throughout the lifespan of the vines-such as altering irrigation, fertilizer, pesticides, and pruning-rootstock choice is made only once. In this study, we assessed eight traits of viticultural importance across two scion varieties ('Chardonnay' and 'Cabernet Sauvignon') grafted to 15 different rootstocks. The vines were grafted near Lodi in San Joaquin County, California, in 1992 and evaluated from 1995 to 1999 in order to determine the relative contributions of variety, year, and rootstock to phenotypic 


\section{Materials and Methods}

Experimental design

In 1991, dormant field grown rootstocks were planted in a Tokay fine sandy loam soil ${ }^{17}$. On

97 April 10th, 1992, scionwood was whip-grafted to the planted rootstock. Rows were oriented eastwest with vine spacing of $2.13 \mathrm{~m}$ by $3.05 \mathrm{~m}$ (Figure $\mathrm{S} 1$ ). The trellis system was a bilateral cordon with fixed foliage wires. The cordon wire was at $1.07 \mathrm{~m}$ height with single foliage wire about $40.6 \mathrm{~cm}$ above. There were two wires $45.7 \mathrm{~cm}$ above the foliage catch wire at either ends of a $63.5 \mathrm{~cm}$ cross arm. The vines were cordon trained and spur pruned.

Prior to vineyard establishment, wine grapes were grown at the site for over 75 years. Initial plantings on this site were ungrafted $V$. vinifera vines. Because of this production history, various pests were considered to be endemic. These included several species of nematodes, phylloxera, many grape associated viruses, and oak root fungus (Armillaria mellea) ${ }^{18}$. All of these soil pests and pathogens can cause considerable economic losses to growers. For this reason, ungrafted vines were not included as a control in this study.

Vines were grafted to the following rootstocks: 'Freedom' ${ }^{24}$, 'Ramsey', '1103 Paulsen', '775 Paulsen', '110 Richter', ‘3309 Couderc', 'Kober 5BB', 'SO4', 'Teleki 5C', '101-14 Mgt', ‘03916’25, '140 Ruggeri', 'Schwarzman', '420 A', and 'K51-32'26. The two scion varieties were 'Chardonnay' (selection FPS 04) and 'Cabernet Sauvignon' (selection FPS 07).

13 The experimental design was a randomized complete block design, split between 'Chardonnay' 114 and 'Cabernet Sauvignon'. There were four replications per treatment (rootstock). There were 
115 eight or nine vines per plot, except for 'Kober 5BB' and 'SO4', which had four or five vines

116 each, to fit all treatments in the block. Data were collected for five years from 1995-1999.

120 Canopy management practices were consistent with regional guidelines and included shoot

121 thinning and leaf removal. Shoot thinning was performed pre-bloom and consisted of removal of 122 non-count shoots (shoots not originating from spur positions). Leaf removal was performed at

123 berry set on the north side of the vine only, to avoid excessive exposure and possible sunburn on

124 the south side. Four to six leaves were removed to open a window in the fruiting zone.

125 Irrigation and vine nutrition programs were standard Best Management Practice for the Lodi

126 District. The irrigation strategy followed a moderate Regulated Deficit Irrigation (RDI) program

127 of about $80 \%$ estimated crop evapotranspiration (ETc) losses, from berry set to veraison ${ }^{19}$.

128 During the post-harvest period, vineyard irrigation was increased to $100 \%$ ETc. The vine

129 nutrition program consisted of the application of approximately $30 \mathrm{lbs}$ of actual nitrogen $(\mathrm{N})$ and

$13060 \mathrm{lbs}$ of actual potassium (K) per acre at post bloom annually. Zinc (Zn) was applied in some

131 years, as local soils tend to be low in native levels of $\mathrm{Zn}^{20}$. All irrigation and nutrients were

132 applied through a drip system, composed of two 0.5 gallons per hour emitters per vine. 
136 Prior to harvest, a 100 berry sample was collected for each plot. The berries were counted and

137 weighed to determine average berry weight. Berries were crushed by hand in plastic collection

138 bags, then strained through cheesecloth to provide juice for analysis of soluble solids content

139 (SSC) $\left({ }^{\circ}\right.$ Brix), $\mathrm{pH}$, and titratable acidity (TA) (g/L). Juice samples were titrated to an endpoint of

$140 \mathrm{pH} 8.2$ to determine $\mathrm{TA}^{21}$. SSC was determined by a temperature compensating Atago N1

141 refractometer $\left(20{ }^{\circ} \mathrm{C}\right)$ and $\mathrm{pH}$ was measured using Beckman $200 \mathrm{pH}$ meter with a dual $\mathrm{KCl}$

142 electrode. Grapes were harvested once they reached an acceptable commercial level for SSC,

143 approximately $24.5^{\circ}$ Brix for 'Cabernet Sauvignon' and $23^{\circ}$ Brix for 'Chardonnay'. Within a

144 particular variety ('Cabernet Sauvignon' or 'Chardonnay') all vines were harvested on the same

145 day (Table S1).

146 The number of clusters per vine and total fruit yield were recorded. In late winter, vines were

147 pruned to retain two node fruiting spurs with a target of 50 nodes retained per vine (Table S1).

148 Dormant pruning weights were measured.

149 Weather data from 1994 to 1999 were downloaded from the National Environmental Satellite,

150 Data, and Information Service for Lodi, California, US (USC00045032) on September 30, 2019.

151 Minimum temperature, maximum temperature, and cumulative precipitation for 1994 to 1999

152 were plotted (Figure S2).

154 Statistical analysis

156 We calculated Ravaz index, a measurement of crop load, by dividing yield by pruning weight

157 from the following dormant season. As a result, our dataset consisted of eight traits, measured

158 across five years, for two scion varieties grafted to 15 different rootstocks (Table S2). The 
experimental design included a replication term (block) to indicate the position of the vines in

160

161

162

the vineyard, which is a randomized complete block design, as evidenced by Figure S1.

The following linear model (Equation 1) was evaluated for each phenotype:

$$
\begin{aligned}
& \text { Phenotype } \sim \text { Year }+ \text { Variety }+ \text { Rootstock }+ \text { Block }+ \text { Year x Rootstock }+ \text { Variety x } \\
& \text { Rootstock }+ \text { Year x Variety }+ \text { Year x Variety x Rootstock }
\end{aligned}
$$

The model was optimized for each phenotype, which included the removal of the three-way interaction in all cases as well as non-significant two-way interactions. All main effects were retained. The code used for analyzing and visualizing the data in this study can be found on $\mathrm{GitHub}^{27}$. All terms in the model were fixed and the analysis was performed in R using the $\operatorname{lm}()$ and $\operatorname{aov}()$ functions from the stats package ${ }^{28}$. After running the model, the distribution of the residuals was examined to check for normality. Next, data were tidied using the tidy() function from the broom $\mathrm{R}$ package ${ }^{29}$. The percent variation was calculated for all terms by calculating the Sum of Squares for a particular term, divided by the Total Sum of Squares, then multiplied by 100 . The results for significant terms ( $\mathrm{p}<0.05$ ), except block (position in the vineyard), were plotted. We included block in our model to account for variation due to position in the vineyard, but we do not discuss those results here. They are included in our supplemental files and explain up to $10.72 \%$ of the variation in a trait (Table S3).

We visualized phenotype data for 'Chardonnay' and 'Cabernet Sauvignon' separately using a loess smoothing line to plot variation across years. For the four traits where rootstock explained the largest amount of variation (i.e. yield, berry weight, pruning weight, and Ravaz index), 
182 rootstocks were compared using a Tukey Test on the model results. For each phenotype, the raw

183 data and a corresponding boxplot were plotted for each rootstock. The estimated marginal means

184 and corresponding $95 \%$ confidence intervals were calculated and plotted using the emmeans

185 package version 1.5.1 in $\mathrm{R}^{30}$ To visualize the variety-specific rootstock effects, we plotted the

186 median values (+/- standard deviation) for 'Cabernet Sauvignon' and 'Chardonnay' separately

187 for each phenotype (Figure S4).

189 Since there are large differences between the two grape varieties used in this study, we calculated

190 the correlation between phenotypes for 'Chardonnay' and 'Cabernet Sauvignon' separately,

191 using a Spearman's correlation in R v.3.6022. To correct for multiple testing, p-values within a

192 particular variety were Bonferroni-corrected. Heatmaps were generated using the heatmap.2

193 function in the gplots $\mathrm{R}$ package $\mathrm{e}^{23}$. All remaining figures were plotted using ggplot2 in $\mathrm{R}^{24}$.

195 Lastly, we determined the potential range of variation induced by rootstock choice by calculating

196 the percent change possible from the lowest rootstock median value to the highest rootstock

197 median value within a particular phenotype. These results were visualized with phenotypes

198 ordered from highest to lowest possible percent change.

\section{$200 \quad$ Results}

201 Phenotype variation across years

202 There was strong variation in phenotypes across the years of the study (Figure 1, Figure S5). The 203 average yield across all rootstocks decreased for both varieties in 1996 (average of $11.3 \mathrm{Kg}$ for

204 'Cabernet Sauvignon' and 7.9 Kg for 'Chardonnay') and 1998 (average of $8.53 \mathrm{Kg}$ for 'Cabernet 
205 Sauvignon' and 8.6 Kg for 'Chardonnay') in contrast to other years where yields ranged from

$206 \quad 10.4 \mathrm{Kg}$ to $15.3 \mathrm{Kg}$ for 'Chardonnay' and 13.3 Kg to $17.3 \mathrm{Kg}$ for 'Cabernet Sauvignon', with the

207 highest yields for both varieties produced in 1997. Similarly, the average number of clusters for

208 either variety was lowest in 1996 and 1998 for 'Cabernet Sauvignon' with values of 80.4 and

20971.8 , respectively, in contrast to other years where values ranged from 111 to 133. For

210 'Chardonnay', the lowest number of clusters, on average, was produced in 1998 (59.9) and

211 although many rootstocks had lower numbers in 1996, the overall average was slightly higher

212 (69.5) than 1995 (63.2). 'Chardonnay' had more clusters, on average, in 1997 (84.1) and 1999

213 (79.5) than other years.

216 In addition to decreased yields in 1996, vines also generally had higher pruning weights, with

217 average values of $2.82 \mathrm{Kg}$ for 'Cabernet Sauvignon' and $2.13 \mathrm{Kg}$ for 'Chardonnay', in

218 comparison to values ranging from $1.01 \mathrm{Kg}$ to $1.43 \mathrm{Kg}$ for 'Cabernet Sauvignon' and $0.74 \mathrm{Kg}$ to

$2191.49 \mathrm{Kg}$ for 'Chardonnay' in other years. However, the relative rankings of the rootstocks were

220 generally consistent across years (Figure 1, Figure S5). 

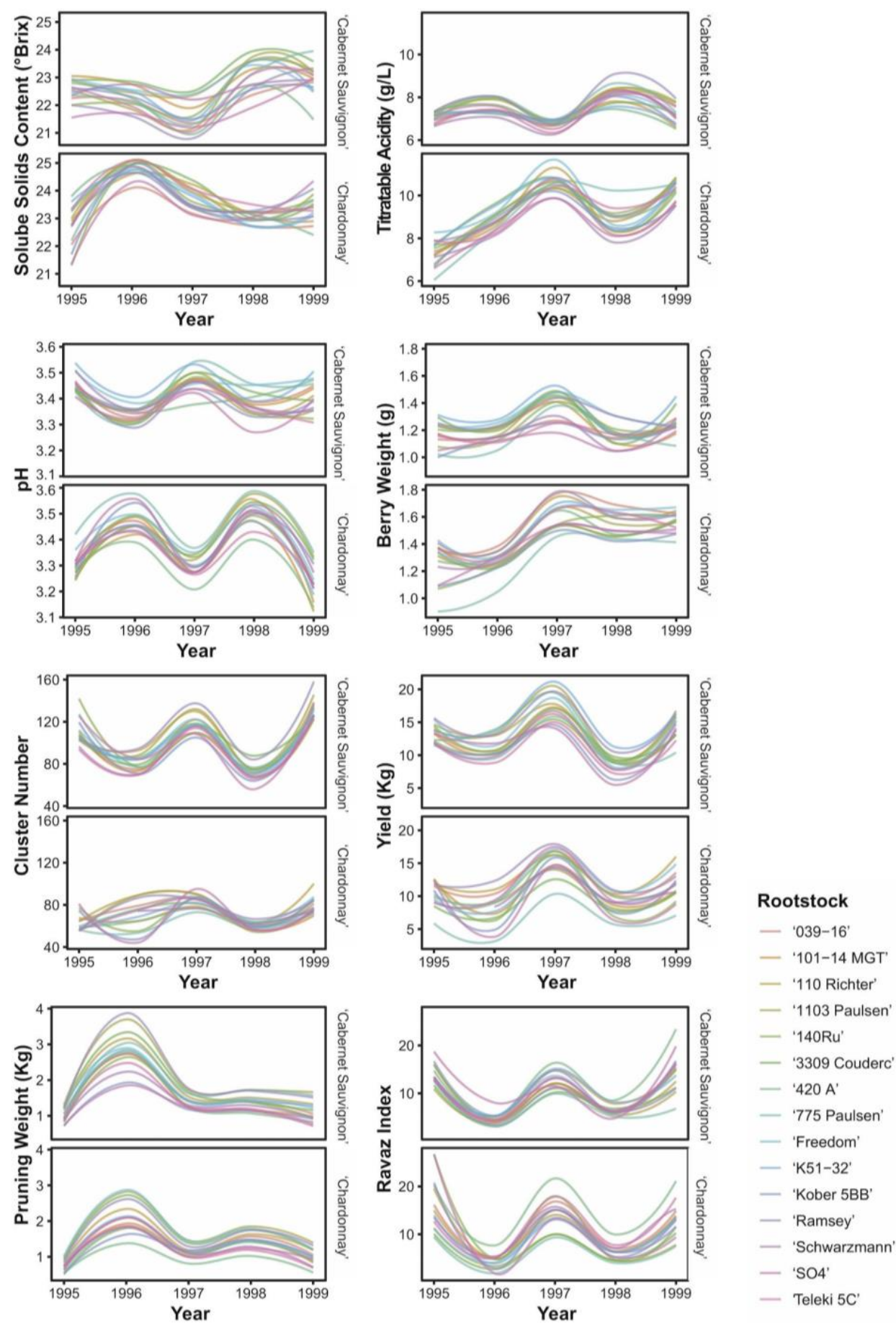

- '1103 Paulsen'

- '140Ru'

- '3309 Couderc'

- ' $420 \mathrm{~A}^{\prime}$

- '775 Paulsen'

- 'Freedom'

- 'K51-32'

- 'Kober 5BB'

- 'Ramsey'

- 'Schwarzmann'

- 'SO4'

- Teleki $5 \mathrm{C}^{\prime}$

Figure 1. Phenotypic variation across years (1995 to 1999) for each rootstock by scion combination. Ravaz index is a measurement of crop load calculated by dividing yield by pruning weight from the following dormant season. Loess smoothing lines are plotted, however, the data are independent and these are for visualization purposes only. Individual data points for this figure are plotted in Figure S5. 


\section{Statistical modeling}

230 Using a linear model (Equation 1), we identified year as the largest source of variation captured

231 by our data (Figure 2). Year was a significant term for all phenotypes, explaining $8.46 \%$ (pH) to

$23252.04 \%$ (pruning weight) of the phenotypic variation. Year explained over $40 \%$ of the variation

233 in pruning weight (52.04\%), Ravaz index (48.64\%), and yield (41.72\%).

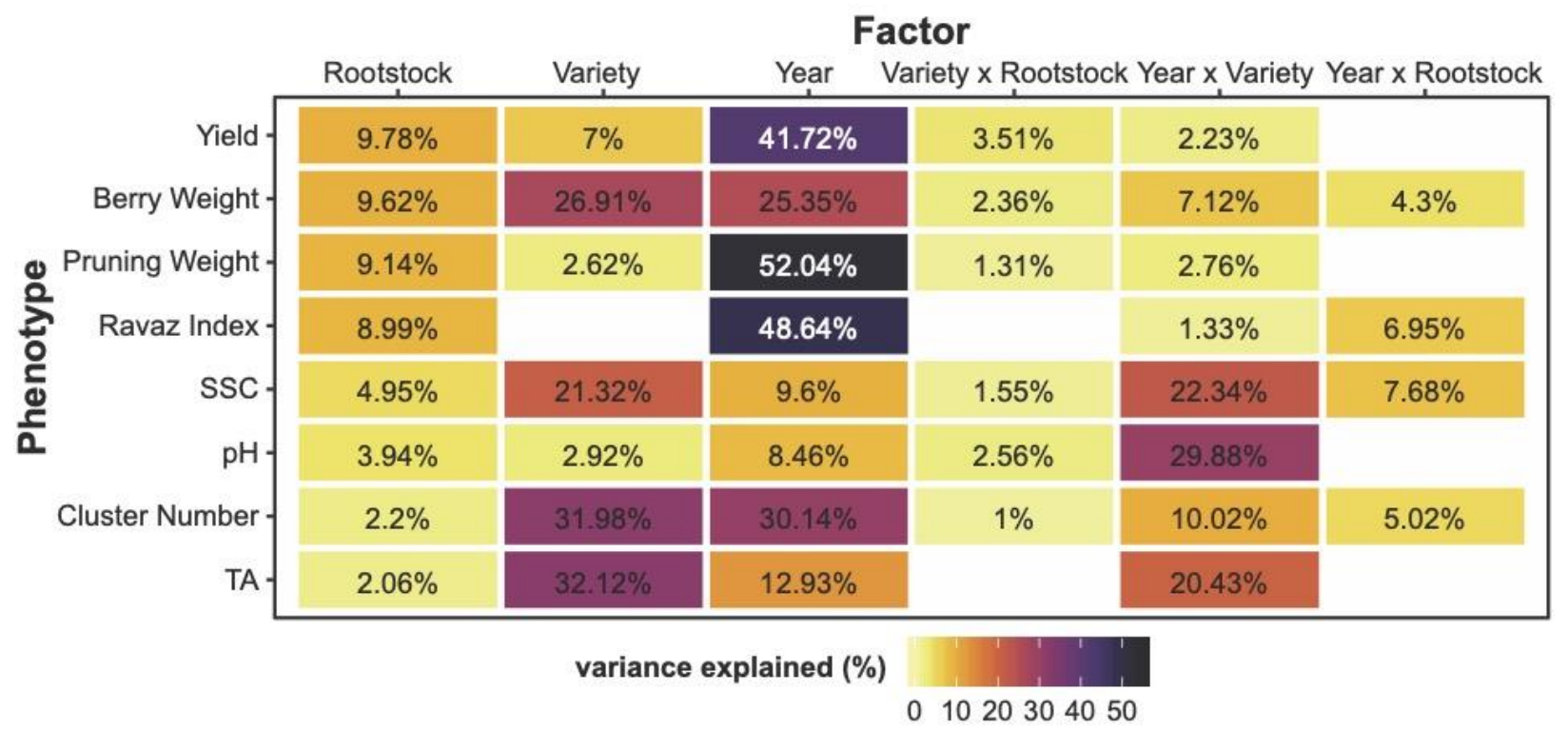

Figure 2. Phenotypic variation explained by factors of interest estimated using a linear model (equation 1). For each phenotype, the linear model was optimized by removing nonsignificant interaction effects. For factors which explain a significant amount of variance ( $\mathrm{p}<$ 0.05), the percent variance explained is indicated using colour. Position in the vineyard (block) was included in the model but is not plotted. Phenotypes are sorted in order of the most variance explained by rootstock.

244 Grapevine variety explained a significant amount of variation in all traits except Ravaz index,

245 with the strongest effect for TA (32.12\%), cluster number (31.98\%), berry weight (26.91\%), and SSC (21.32\%). The interaction between year and variety was significant for all traits, and over 
$20 \%$ of the variation in $\mathrm{pH}(29.88 \%), \mathrm{SSC}(22.34 \%)$, and TA $(20.43 \%)$ could be explained by

248 this term.

Rootstock had a significant effect on all phenotypes and explained between $8.99 \%$ and $9.78 \%$ of the variation in yield, berry weight, pruning weight, and Ravaz index. For yield, pruning weight, $\mathrm{pH}$, and TA, the interaction between rootstock and year was removed from the model because it did not explain a significant amount of variation in the trait. For the remaining traits, the interaction between rootstock and year explained $4.31 \%$ to $7.68 \%$ of the variation (Figure 2).

While the interaction between variety and rootstock was retained as a significant term for all phenotypes except TA and Ravaz index, it explained less than $4 \%$ of the variation in any given phenotype.

\section{Comparing rootstock performance}

262 Focusing on the phenotypes in which rootstock showed the strongest effect, we plotted the 263 distributions for yield (9.78\%), berry weight (9.62\%), pruning weight $(9.14 \%)$, and Ravaz index

264 (8.99\%) and compared each of the 15 rootstocks using a Tukey test (Figure 3). Across these

265 phenotypes, 'Ramsey' had among the highest yields, berry weights, and pruning weights, and

266 one of the lowest Ravaz indexes. The yield for 'Ramsey' was significantly higher than eight of

267 the other rootstocks evaluated. Similarly, 'Freedom' ranked within the top four for yield, berry

268 weight, and pruning weight measurements, but ranked 11th for Ravaz index. However,

269 'Freedom' and 'Ramsey' only had a significantly lower Ravaz index than '420 A'. 

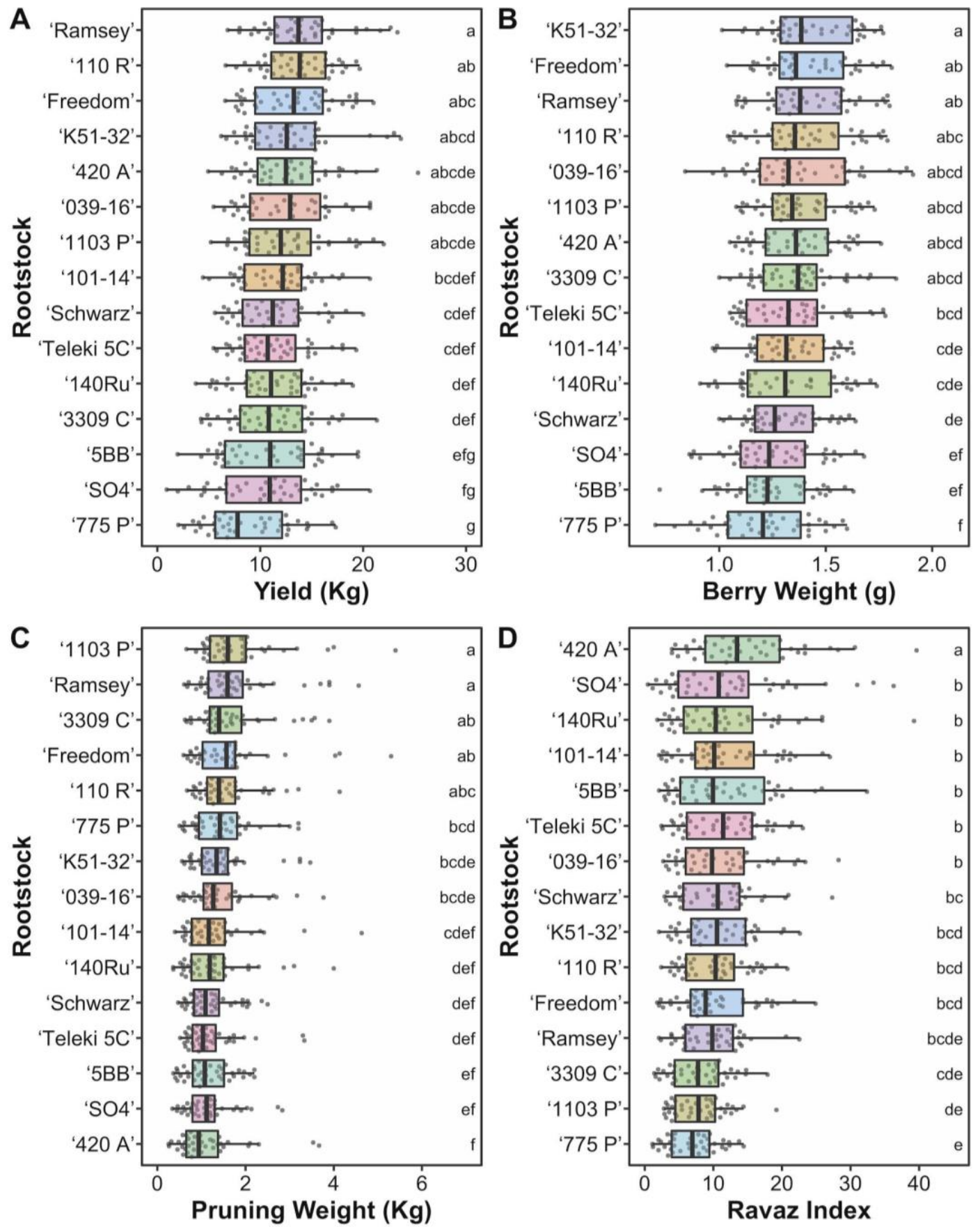

272 Figure 3. Variation in (A) yield, (B) berry weight, (C) pruning weight, and (D) Ravaz index across vines grafted to 15 different rootstocks. Rootstocks are ordered from highest to lowest mean values. Tukey test results are reported from a linear model accounting for variation in variety, year, position in the vineyard (block), and applicable interaction effects. Rootstocks with the same letter (indicated inside the plot) are not significantly different from each other. For

277 estimated marginal means see Figure S3. 
279 The rootstock ' 775 P' generated the lowest yields and smallest berries, with only 'SO4' and

280 '5BB' not differing significantly for these two phenotypes. In contrast, '775 P' was ranked 6th

281 for pruning weight, which resulted in a significantly lower Ravaz index than all other rootstocks

282 except '3309 C', '1103 P', and 'Freedom', although this trend is likely due primarily to the low

283 yield of 'Chardonnay' grafted to '775 P' (Figure S4). In comparison, '420 A' ranked 5th for

284 yield and had the lowest pruning weight, thus resulting in a Ravaz index which was significantly

285 higher than all other rootstocks.

\section{Correlation between traits}

288 For both 'Chardonnay' and 'Cabernet Sauvignon', Ravaz index was significantly correlated with 289 most other phenotypes with the exception of TA ('Chardonnay') and SSC ('Cabernet

290 Sauvignon') (Figure 4, Table S4). Ravaz index was positively correlated with cluster number for

291 'Chardonnay' $\left(\mathrm{r}=0.250, \mathrm{p}=3.398 \times 10^{-4}\right)$ and 'Cabernet Sauvignon' $\left(\mathrm{r}=0.671, \mathrm{p}<1 \times 10^{-15}\right)$.

292 Yield was not significantly correlated with pruning weight for either variety but it was positively

293 correlated with cluster number ('Chardonnay': $r=0.634, p<1 \times 10^{-15}$; 'Cabernet Sauvignon': $r$

$294=0.722, \mathrm{p}<1 \times 10^{-15}$ ) and berry weight ('Chardonnay': $\mathrm{r}=0.489, \mathrm{p}<1 \times 10^{-15} ;$ 'Cabernet

295 Sauvignon': $\left.\mathrm{r}=0.579, \mathrm{p}<1 \times 10^{-15}\right)$. 
A 'Chardonnay'

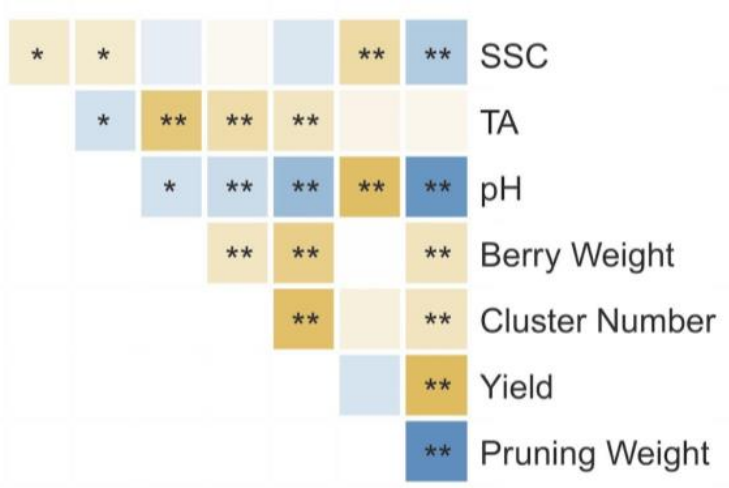

Ravaz Index

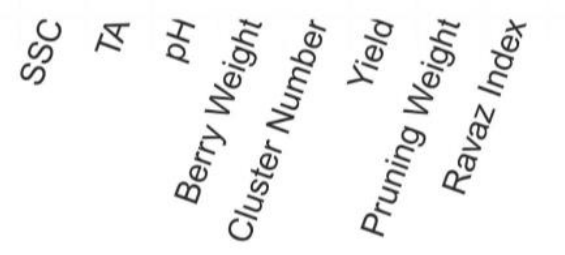

B 'Cabernet Sauvignon'

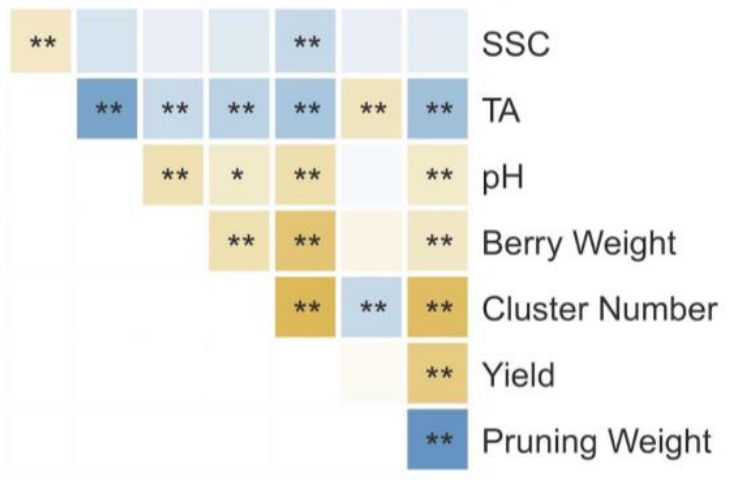

Ravaz Index

\section{8} than $15 \%$.



$$
\begin{gathered}
\text { Bonferroni corrected } p \text {-value } \\
* * p<0.05 \\
{ }^{*} p<0.01
\end{gathered}
$$

\section{Figure 4. Spearman's correlations among phenotypes for (A) 'Chardonnay' and (B)} 'Cabernet Sauvignon'. P-values were Bonferroni-corrected for multiple comparisons with a particular variety.

\section{Range of rootstock effects}

Lastly, we evaluated the percent change between the best and worst performing rootstocks for each phenotype (Figure 5, Table S5). The percent change ranged from 3.10\% for SSC to $93.78 \%$ for Ravaz index. In addition to Ravaz index, cluster number (35.42\%), pruning weight (70.82\%), and yield (77.35\%) all increased by over 30\%, while the remaining phenotypes increased by less 




Figure 5. Percent change in each phenotype from rootstock with the lowest median to the rootstock with the highest median. Phenotypes are ordered from largest percent change to lowest percent change. Raw values are also listed.

314 Discussion

316 In California, most wine regions annually receive sufficient rainfall during the dormant season to

317 support desired canopy growth. However, there are years where low dormant season rainfall may

318 reduce canopy growth ${ }^{31}$. Previous work examining 'Merlot' vines across two years in California

319 found that soil moisture level during the dormant season impacted both vegetative and

320 reproductive growth, even when irrigation is applied after budbreak ${ }^{31}$. In our study, there was

321 less rainfall during the 1994 and 1997 dormant seasons when floral initiation would have

322 occurred (Figure S2). While the reduction in yield we observed in 1998 may be due to a dry

3231997 dormant season, the dormant season prior to 1996 had higher rainfall and it's unclear why 
324 the yield was not higher (Figure 1). Thus, at least for the 1998 growing season, a reduction in

325 rainfall the previous year may have had a more severe impact on reproductive growth in contrast

326 to vegetative growth.

327

328 In addition to the impact of rainfall, overcropping (too much fruit) has been considered as a

329 source of alternate (biennial) bearing, with high yields in one year reducing yield in the

330 subsequent year. Growers may be concerned that mechanical pruning can lead to overcropping,

331 however, the vines in this study were hand-pruned to a target of 50 nodes per vine. In addition,

332 previous work on both 'Sultana' and 'Concord' grapes found variation in yield was primarily due

333 to environmental factors and management practices, rather than alternate bearing because of

334 overcropping ${ }^{32,33}$. Therefore, in our study, it was most likely the low precipitation and not

335 overcropping in 1997 which was primarily responsible for reducing yields in 1998.

337 In contrast to our study (Figure 1), previous work found that the reduction to pruning mass due to

338 dormant season rainfall was more severe than the reduction to yield, increasing the Ravaz index

339 for vines which did not receive rainfall ${ }^{31}$. While this is not consistent with our results, we do find

340 that year is the largest source of variation in growth-related traits (Figure 2), confirming that

341 variable environmental conditions between years, such as access to water during the dormant

342 season, plays a crucial role in plant growth and development.

344 Variation and consistency of scion and rootstock effects

345 During the growing season, grape growers can use management practices such as irrigation to

346 partly buffer against year-to-year variation ${ }^{34}$. The vines in this study were all irrigated using the 
same management practices across five years, with a moderate RDI program of $80 \%$ from berry set to veraison, therefore reducing the impact of weather fluctuations during the growing season. When included in a linear model (Figure 2), variety explained over $20 \%$ of the variation we observed for TA, berry weight, and SSC, indicating that there is a strong variety-specific effect on many berry characteristics. Year, or vintage, had a significant interaction with variety for all phenotypes and explained over $20 \%$ of the variation in berry chemistry measurements such as $\mathrm{pH}, \mathrm{SSC}$, and TA. Even with consistent water management, berries from each variety responded differently to environmental conditions. In comparison, for growth measurements such as yield and pruning weight there was less variation explained by year by variety interaction, indicating the years with low or high growth for 'Chardonnay' had a similar impact on 'Cabernet Sauvignon'. Thus, the effect of year on growth was relatively similar across different grapevine varieties, while the effect on berry chemistry differed between varieties. between rootstock and year was not a significant term for yield, pruning weight, $\mathrm{pH}$ or TA, and explained less than $8 \%$ of the variation for the remaining phenotypes. We found that the effect of a rootstock was generally consistent between 'Chardonnay' and 'Cabernet Sauvignon', with the

364 interaction between variety and rootstock explaining very little phenotypic variation (less than $3654 \%$ ). This suggests that grape growers should place great emphasis on rootstock choice as a 366 critical decision during vineyard planning as performance of one rootstock, relative to others, is generally consistent over time and between varieties. 


\section{Effects of rootstocks and their interaction with environment}

371 The choice of rootstock is particularly important for growth-related traits such as yield, pruning

372 weight, berry size, and Ravaz index, where rootstock effects explained at least $9 \%$ of the

373 variation (Figure 2). In contrast to our study, previous work examining nine grape varieties

374 grown ungrafted and grafted to four different rootstocks found that yield and berry weight were

375 not affected by rootstock ${ }^{35}$. However, similar to our work, the study identified that vine and yield

376 components were more responsive to rootstock than fruit composition variables ${ }^{35}$. Our results are

377 also consistent with previous work identifying a significant difference in yield, pruning weight,

378 and berry weight of 'Shiraz' vines grafted to different rootstocks and measured across six

379 years $^{18}$. That said, while rootstock can have a significant impact on yield, environmental factors

380 including location, climate, and soil, generally have a much larger influence on this trait ${ }^{19,36}$.

In long-lived perennial plants where significant year-to-year variation can occur, the collection of data across multiple years is a valuable tool for untangling the effect of the environment. By evaluating the vines in this study across five years, we were able to account for the variation due to year in our model and determine how much of the variation was due to rootstock (Figure 3). Similarly, a recent seven year study examined 'Cabernet Sauvignon' grafted to three different rootstocks. The study found no significant effect of rootstock on pruning weight, although yield and berry weight did differ significantly ${ }^{37}$. When comparing the rootstocks which overlapped with our study, the authors found similar results: '101-14 Mgt' and '420 A' did not differ

390 significantly for yield and berry weight, but '420 A' had a significantly higher Ravaz index ${ }^{37}$. 
A 25 year study that measured 'Cabernet Sauvignon' grafted to three different rootstocks found that Ravaz index was significantly affected by rootstock choice, but only after 7 years of

394 planting. Similarly, yields across rootstocks only differed after 15 years ${ }^{38}$. Although we detect

395 variation in vines which had been planted for three to seven years, our dataset includes a much

396 broader representation of rootstocks. The effects observed in our study may not only be due to

397 the young age of the vines examined here, but also due to the particular soil of the experimental

398 plot. For example, previous work found that in a vineyard severely infected with nematodes,

399 grafting 'Chardonnay' to 15 different rootstocks increased yield by up to 7 times and pruning

400 weight by up to 23-fold when compared to ungrafted vines. Rootstocks varied in their resistance

401 and tolerance to nematodes, with rootstock parentage influencing both yield and pruning

402 weight $^{21}$. Given that grapevines may remain in the ground for at least 20 years, additional long

403 term studies across multiple locations are needed in order to determine how the effect of

404 rootstocks changes over time and under different external conditions including environment and 405 soil.

406

Rootstocks affect growth-related scion phenotypes

408 Generally, rootstocks resulting in large values of one growth-related phenotype also resulted in

409 large measures of other growth-related phenotypes (Figure 4). For example, rootstocks that

410 generated higher yields generally also produced larger berries. While cluster number was more

411 highly correlated with yield than berry weight, much more variation in berry weight could be

412 explained by rootstock, indicating that increased yields due to rootstock were primarily a result

413 of increased berry weight and not additional clusters. This suggests that rootstock choice does

414 not influence floral initiation, but rather influences water uptake, which leads to variation in 
415 berry weight. While high yields are generally desirable, the ratio of skin-to-pulp is an important

416 consideration for vinification, and this ratio is reduced when berries take on more water.

417 Previous work also demonstrated that in addition to decreasing fruit size, reducing water in

418 'Cabernet Sauvignon' increased desirable characteristics such as the concentrations of skin

419 tannin and anthocyanins ${ }^{39}$. Therefore, while the use of a rootstock to increase yields is beneficial,

420 this has to be balanced with ensuring that the berries maintain a desirable size, possibly through a

421 reduction in irrigation for more vigorous rootstocks.

423 While increased reproductive growth leading to increased yields is economically beneficial, if

424 the vegetative growth increases at the same rate, the Ravaz index, or crop load, of the vine will

425 remain consistent. Increased vegetative growth results in higher vine management costs, such as

426 pruning and leaf thinning. We demonstrated that Ravaz index was correlated with most of the

427 other phenotypes we measured (Figure 4). This suggests that the balance between reproductive

428 and vegetative growth in a vine is associated with many other characteristics of that vine.

429 However, pruning weight and yield were not correlated, likely because all vines were pruned to a

430 similar size and shoot number to prevent overcropping, but the number of clusters per shoot

431 differed. As a result, higher yields were positively correlated with both berry weight and cluster

432 number, but the correlation with cluster number was higher for both varieties, indicating that the

433 primary source of increased yield was more clusters and not larger berries. In some instances,

434 therefore, rootstock choice may increase reproductive growth of a vine without an increase in

435 vegetative growth and its associated costs. 
437 The choice of one roostock over another can result in nearly a two-fold difference in growth-

438 related traits like yield, Ravaz index and pruning weight but has little effect on berry on the

439 chemistry measurements assessed in this study, in particular SSC and pH (Figure 5). Previous

440 studies have also found small differences in berry chemistry such as SSC with large variation in

441 growth, such as yield, due to rootstock21,43.

\section{Potential causes of rootstock-induced variation in growth}

444 While we were unable to evaluate it directly, we find it likely that much of the variation in

445 growth that can be attributed to rootstock in our study is due to increased water uptake by vines

446 grafted to certain rootstocks. Variation in water uptake is generally the result of some

447 combination of water uptake efficiency, the size and surface area of the root system, and

448 stomatal regulation to reduce water loss, among other factors ${ }^{12}$. For example, 'Ramsey' and

449 'Freedom' generally had high yields, large berries, and high pruning weights (Figure 3).

450 Similarly, in an Australia study, 'Shiraz' vines grown with irrigation and grafted to 'Ramsey' or

451 'Freedom' rootstocks yielded more fruit than ungrafted vines and than vines grafted on the other

452 five rootstock varieties assessed, indicating that these rootstocks tend to increase yield and

453 pruning weight ${ }^{40}$. Other work found a rootstock-dependent effect of irrigation on some yield

454 components such as cluster number and berry weight, but not on yield itself ${ }^{41}$. In our study, all

455 vines were irrigated equally, which may have led to a rootstock-specific effect on water uptake

456 which ultimately contributed to variation in yield and could be further controlled with rootstock-

457 specific irrigation regimes. 
In addition to variation water uptake, it is possible some variation in growth is due to variation in

460 disease resistance. While phylloxera is a concern in the region, all vines were grafted to

461 rootstocks which should provide protection. Additionally, there is the potential for grapevine

462 fanleaf virus at this site. One of the key symptoms of fanleaf degeneration is a decrease in fruit

463 set which leads to a lower yield ${ }^{42}$. Given that only vines grafted to '039-16' would have fanleaf

464 protection in this study, and the yield of vines grafted to '039-16' is not significantly higher than

465 other rootstocks (Figure 3A) which do not offer protection, indicating that it is likely not a severe

466 concern in this vineyard. Thus, while there may be some variation in rootstock tolerance to other

467 pests and pathogens, this is unlikely to be a major factor in this study.

\section{Conclusion}

470 Increasing yield, especially during the early years of production, can have a dramatic influence

471 on the profitability of a vineyard and the results of this study clearly indicate that selection of the

472 right rootstock is a valuable tool that grape growers can use to help control vine size and yield.

473 These results should be taken into account when considering which rootstock to select,

474 particularly in the San Joaquin Valley where this study was performed, with additional work

475 needed to verify the effect of each rootstock across different geographic locations. Future work

476 can explore if the early advantage provided by rootstock is maintained throughout the life of a

477 vineyard.

478

479 
Supplemental information

Figure S1. Vineyard map of rootstock evaluation trial.

Figure S2. Variation in maximum temperature $\left({ }^{\circ} \mathbf{F}\right)$, minimum temperature $\left({ }^{\circ} \mathbf{F}\right)$ and cumulative precipitation (inches) measured from January 1994 to December 1999 in Lodi, California, US.

Figure S3. Estimated marginal means with $95 \%$ confidence interval for variation in (A) different rootstocks. Rootstocks are ordered from highest to lowest mean values. Linear models Tukey test results are reported from a linear model accounting for variation in variety, year, position in the vineyard (block), and applicable interaction effects.

Figure S4. Median values (+/- standard deviation) for each phenotype for 'Chardonnay' and 'Cabernet Sauvignon’ grafted to each rootstock.

Figure S5. Phenotypic variation across years (1995 to 1999) for each rootstock by scion combination with individual data points plotted. Loess smoothing lines are also plotted, 501 however, the data are independent and these are for visualization purposes only. Ravaz 502 index is a measurement of crop load calculated by dividing yield by pruning weight from 503 the following dormant season. 
Table S1. Harvest and pruning dates for 'Chardonnay' and 'Cabernet Sauvignon' vines sampled from 1995-1999.

Table S2. Phenotype data collected from 1995 to 1999 for 'Chardonnay' and 'Cabernet Sauvignon' vines grafted to 15 different rootstocks.

511 Table S3. Linear model results for each phenotype. Each model was optimized for each

512 phenotype: the main effects were retained in all cases but non-significant interactions were 513 removed.

Table S4. Results of Spearman's correlation between phenotypes for 'Chardonnay' and 'Cabernet Sauvignon'. P-values were Bonferroni-corrected for comparison within each variety. median, minimum median, average median are included as well as the maximum percent change

520 (from minimum to maximum median) and average percent change across rootstocks.

\section{Data Availability}

524 All data supporting the results of this manuscript have been included as supplementary materials

525 (Table S2). The code used to analyze the data and generate the figures in this manuscript has

526 been made publicly available on $\mathrm{GitHub}^{27}$. 


\section{Acknowledgments}

ZM was supported by the National Science Foundation Plant Genome Research Program

1546869. SM was supported by the National Sciences and Engineering Council of Canada. We gratefully acknowledge all of the individuals involved in maintaining the vineyard evaluated for this study, in particular Ernie and Jeff Dosio (Pacific AgriLands Inc., Modesto, CA).

\section{Conflicts of interest}

PC, LMJ, and RKS were employed by E. \& J. Gallo Winery. The remaining authors declare that could be construed as a potential conflict of interest.

\section{Authors' Contributions}

544 PV conceived this work and led the collection of the data. LMJ organized the data. ZM analyzed

545 the data and wrote the manuscript. PC, SM, and DHC provided feedback in data analysis and 546 interpreting the results. PC, RKS, and DHC provided project oversight and guidance. All authors

547 reviewed the manuscript.

\section{References}

550 1. Webster AD. Rootstock and interstock effects on deciduous fruit tree vigour, precocity, and yield $551 \quad$ productivity. N Z J Crop Hortic Sci. 1995;23(4):373-382. doi:10.1080/01140671.1995.9513913

552 2. Fazio G, Wan Y, Kviklys D, et al. Dw2, a new dwarfing locus in apple rootstocks and its 
relationship to induction of early bearing in apple scions. J Am Soc Hortic Sci. 2014;139(2):87-98.

3. Warschefsky EJ, Klein LL, Frank MH, et al. Rootstocks: Diversity, Domestication, and Impacts on Shoot Phenotypes. Trends Plant Sci. 2016;21(5):418-437. doi:10.1016/j.tplants.2015.11.008

4. Ollat N, Bordenave L, Tandonnet JP, Boursiquot JM, Marguerit E. Grapevine rootstocks: origins and perspectives. Acta Hortic. 2016;(1136):11-22. doi:10.17660/ActaHortic.2016.1136.2

5. Lider LA, Andrew Walker M, Wolpert JA. Grape rootstocks in California vineyards: the changing picture. In: International Symposium on Viticulture and Enology 388. ; 1995:13-18.

6. Riaz S, Pap D, Uretsky J, et al. Genetic diversity and parentage analysis of grape rootstocks. Theor Appl Genet. Published online March 8, 2019. doi:10.1007/s00122-019-03320-5

7. Lider LA. The performance of vigorous nematode resistant rootstocks in field trials in the San Joaquin Valley. Am J Enol Vitic. 1959;10(3):147-151.

8. Cousins P, Walker M. Genetics of resistance to Meloidogyne incognita in crosses of grape rootstocks. Theor Appl Genet. 2002;105(5):802-807. doi:10.1007/s00122-002-0977-2

9. Hwang C-F, Xu K, Hu R, Zhou R, Riaz S, Walker MA. Cloning and characterization of XiR1, a locus responsible for dagger nematode resistance in grape. Theor Appl Genet. 2010;121(4):789-799. doi:10.1007/s00122-010-1349-y

10. Ferris H, Zheng L, Walker M. Resistance of grape rootstocks to plant-parasitic nematodes. $J$ Nematol. 2012;44(4):377.

11. Zhang X, Walker RR, Stevens RM, Prior LD. Yield-salinity relationships of different grapevine (Vitis vinifera L.) scion-rootstock combinations. Aust J Grape Wine Res. 2002;8(3):150-156. doi:10.1111/j.1755-0238.2002.tb00250.x

12. Serra I, Strever A, Myburgh PA, Deloire A. Review: the interaction between rootstocks and cultivars (Vitis vinifera L.) to enhance drought tolerance in grapevine. Aust J Grape Wine Res. 2014;20(1):1-14. doi:10.1111/ajgw.12054

13. Migicovsky Z, Harris ZN, Klein LL, et al. Rootstock effects on scion phenotypes in a 'Chambourcin' experimental vineyard. Hortic Res. 2019;6(1):64. doi:10.1038/s41438-019-0146-2

14. Gautier A, Cookson SJ, Lagalle L, Ollat N, Marguerit E. Influence of the three main genetic backgrounds of grapevine rootstocks on petiolar nutrient concentrations of the scion, with a focus on phosphorus. OENO One. 2020;54(1):1-13. doi:10.20870/oeno-one.2020.54.1.2458

15. Gautier A, Cookson SJ, Hevin C, Vivin P, Lauvergeat V, Mollier A. Phosphorus acquisition efficiency and phosphorus remobilization mediate genotype-specific differences in shoot phosphorus content in grapevine. Tree Physiol. 2018;38(11):1742-1751. doi:10.1093/treephys/tpy074

16. Cheng J, Wei L, Mei J, Wu J. Effect of rootstock on phenolic compounds and antioxidant properties in berries of grape (Vitis vinifera L.) cv. 'Red Alexandria.' Sci Hortic. 2017;217:137-144. doi:10.1016/j.scienta.2017.01.037

17. Walker RR, Read PE, Blackmore DH. Rootstock and salinity effects on rates of berry maturation, ion accumulation and colour development in Shiraz grapes. Aust J Grape Wine Res. 2000;6(3):227239.

18. Jones TH, Cullis BR, Clingeleffer PR, Rühl E. Effects of novel hybrid and traditional rootstocks on vigour and yield components of Shiraz grapevines. Aust J Grape Wine Res. 2009;15(3):284-292.

19. Keller M. Chapter 6: Developmental physiology. In: The Science of Grapevines. 3rd edition. Academic Press; 2020:199-277.

20. Kidman CM, Mantilla SO, Dry PR, McCarthy MG, Collins C. Effect of water stress on the reproductive performance of Shiraz (Vitis vinifera L.) grafted to rootstocks. Am J Enol Vitic. 2014;65(1):96-108.

21. McCarthy MG, Cirami RM. The Effect of Rootstocks on the Performance of Chardonnay from a Nematode-Infested Barossa Valley Vineyard. Am J Enol Vitic. 1990;41(2):126-130.

22. Walker RR, Blackmore DH, Clingeleffer, R P, Correll RL. Rootstock effects on salt tolerance of irrigated field-grown grapevines (Vitis vinifera L. cv. Sultana) 2. Ion concentrations in leaves and juice. Aust J Grape Wine Res. 2004;10(2):90-99. 
604

605

606

607

608

609

610

611

612

613

614

615

616

617

618

619

620

621

622

623

624

625

626

627

628

629

630

631

632

633

634

635

636

637

638

639

640

641

642

643

644

645

646

647

648

649

650

23. Mantilla SMO, Collins C, Iland PG, et al. Shiraz (Vitis vinifera L.) berry and wine sensory profiles and composition are modulated by rootstocks. Am J Enol Vitic. 2018;69(1):32-44.

24. Garris A, Cousins P, Ramming D, Baldo A. Parentage Analysis of Freedom Rootstock. Am J Enol Vitic. 2009;60(3):357.

25. Walker MA, Lider LA, Goheen AC, Olmo HP. VR 039-16 grape rootstock. HortScience. 1991;26(9):1224-1225.

26. May P. Using Grapevine Rootstocks: The Australian Perspective. Winetitles; 1994.

27. Migicovsky Z. GitHub. Published 2021. Accessed February 19, 2021.

https://github.com/zoemigicovsky/grapevine_rootstocks

28. R Core Team. R: A Language and Environment for Statistical Computing.; 2020. https://www.Rproject.org/

29. Robinson D, Hayes A, Couch S. Broom: Convert Statistical Objects into Tidy Tibbles.; 2021. https://CRAN.R-project.org/package=broom

30. Lenth R. Emmeans: Estimated Marginal Means, Aka Least-Squares Means.; 2020. https://CRAN.Rproject.org/package=emmeans

31. Mendez-Costabel MP, Wilkinson KL, Bastian SEP, et al. Effect of winter rainfall on yield components and fruit green aromas of Vitis vinifera L. cv. Merlot in California. Aust J Grape Wine Res. 2014;20(1):100-110. doi:10.1111/ajgw.12060

32. Keller M, Mills LJ, Wample RL, Spayd SE. Crop Load Management in Concord Grapes Using Different Pruning Techniques. Am J Enol Vitic. 2004;55(1):35-50.

33. Antcliff A. A comparison of cropping levels in the Sultana. Published online 1965.

34. Medrano H, Escalona JM, Cifre J, Bota J, Flexas J. A ten-year study on the physiology of two Spanish grapevine cultivars under field conditions: effects of water availability from leaf photosynthesis to grape yield and quality. Funct Plant Biol. 2003;30(6):607-619.

35. Reynolds AG, Wardle DA. Rootstocks Impact Vine Performance and Fruit Composition of Grapes in British Columbia. HortTechnology. 2001;11(3):419-427. doi:10.21273/HORTTECH.11.3.419

36. Keller M, Mills LJ, Harbertson JF. Rootstock effects on deficit-irrigated winegrapes in a dry climate: Vigor, yield formation, and fruit ripening. Am J Enol Vitic. 2012;63(1):29-39.

37. Hickey CC, Hatch TA, Stallings J, Wolf TK. Under-Trellis Cover Crop and Rootstock Affect Growth, Yield Components, and Fruit Composition of Cabernet Sauvignon. Am J Enol Vitic. 2016;67(3):281-295. doi:10.5344/ajev.2016.15079

38. Ollat N, Tandonnet JP, Lafontaine M, Schultz HR. Short and long term effects of three rootstocks on Cabernet Sauvignon vine behaviour and wine quality. In: Workshop on Rootstocks Performance in Phylloxera Infested Vineyards 617. ; 2003:95-99.

39. Roby G, Harbertson JF, Adams DA, Matthews MA. Berry size and vine water deficits as factors in winegrape composition: anthocyanins and tannins. Aust J Grape Wine Res. 2004;10(2):100-107.

40. Mccarthy MG, Cirami RM, Furkaliev DG. Rootstock response of Shiraz (Vitis vinifera) grapevines to dry and drip-irrigated conditions. Aust J Grape Wine Res. 1997;3(2):95-98. doi:10.1111/j.17550238.1997.tb00121.x

41. Stevens RM, Pech JM, Gibberd MR, Walker RR, Nicholas PR. Reduced irrigation and rootstock effects on vegetative growth, yield and its components, and leaf physiological responses of Shiraz. Aust J Grape Wine Res. 2010;16(3):413-425. doi:10.1111/j.1755-0238.2010.00102.x

42. Walker MA, Wolpert JA, Weber E. Viticultural characteristics of VR hybrid rootstocks in a vineyard site infected with grapevine fanleaf virus. Vitis. 1994;33(1):19-23.

43. Cirami R, McCarthy M, Glenn T. Comparison of the effects of rootstock on crop, juice and wine composition in a replanted nematode-infested Barossa Valley vineyard. Aust J Exp Agric. 1984;24(125):283-289. 